\title{
CONFORMITY TO OCCUPATIONAL SAFETY AND HEALTH REGULATIONS IN MALAYSIAN SMALL AND MEDIUM ENTERPRISES
}

\author{
${ }^{1}$ Baba Md Deros, ${ }^{2}$ Ahmad Rasdan Ismail, ${ }^{1}$ Jaharah A. Ghani and ${ }^{1}$ Mohd Yusri Mohd Yusof \\ ${ }^{1}$ Department of Mechanical and Materials Engineering, Faculty of Engineering and Built Environment, \\ University Kebangsaan Malaysia, Bangi Selangor, 43600, Malaysia \\ ${ }^{2}$ Sports and Human Engineering Group, Faculty of Mechanical Engineering, \\ Universiti Malaysia Pahang, 26600 Pekan, Pahang, Malaysia \\ Received 2012-09-03; Revised 2012-10-01; Accepted 2014-01-20
}

\begin{abstract}
Regulation on occupational safety and health in Malaysia had evolved from the prescriptive factory and machinery act to a self-regulated occupational safety and health act. However, from the authors' observation the high standards of occupational safety and health culture that surpass the legal requirement were not widely practiced by Small and Medium Enterprises (SMEs). The two main objectives of this study are: First, first, to identify and determine the level of conformity and second, to investigate the reasons of nonconformity to occupational safety and health act regulation in SMEs involved the chemical industry sub-sectors. The survey questionnaire was distributed to 150 SMEs in chemical industry sub-sectors. Forty one of the survey questionnaires were completed and returned, giving a response rate of $27.3 \%$ for the survey. Survey data were analyzed statistically using the SPSS software. The survey results revealed that an overwhelming majority (92.7\%) of the respondents from SMEs are likely not conforming to the basic requirement of occupational safety and health act. In addition to this, the survey also found that only $3.1 \%$ of the management personnel can be considered competent in terms of knowledge, skill and ability in carrying out occupational safety and health regulation within their respective organization. While, $96.9 \%$ of the respondents that participated in the survey can be considered not competent. The authors hope results of this survey could assist the relevant authorities in formulating a better policy and strategy for implementing occupational safety and health in SMEs involved in chemical industry sub-sectors.
\end{abstract}

Keywords: Occupational Safety and Health, Industry, SMEs, Chemical

\section{INTRODUCTION}

The regulation on public safety can be traced back to the era of King Hammurabi in Babylon since 2500 BC. The infamous Hammurabi Code inscribed on stone dictates that any person who is guilty of causing the death of a person would be punishable by death (Bahari, 2006; Hussin et al., 2005). After more than four millenniums, the safety regulation had evolved with most changes occurred after the industrial revolution (Bahari, 2006; Hassan, 2003). In our modern world, industrial safety aspect is no longer regarded as trivial and any accident is no longer being accepted merely as fate. More positive efforts are being taken by all the stakeholders to improve the level of occupational safety and health.

\subsection{Occupational Safety and Health Management in SMEs}

A management perspective on occupational risk prevention is reflected in the company's focus on safety management systems. SMEs represent a vast majority of workforce in all over the world. However, very limited Corresponding Author: Baba Md Deros, Department of Mechanical and Materials Engineering, Faculty of Engineering and Built Environment, University Kebangsaan Malaysia, Bangi Selangor, 43600, Malaysia 
evidence is available on the managerial influence on occupational risk prevention came from SMEs (Swuste, 2008). There is a general assumption that SMEs are characterized by a high-hazard, high-risk environment and poor management strategies to prevent these risks. A link was found between a lack of knowledge about occupational hazards and poor housekeeping, mechanical, physical, chemical and ergonomic hazards on the other hand (Takala, 1993).

The most dominant problem faced by SMEs relates to the formal system of safety management, laws and regulations. In addition, they may have poor contacts with supportive organizations that provide them with relevant information on risk prevention and they do not have the time, means or the inclination to pursue the information themselves (Champoux and Brun, 2003; Walker and Tait, 2004).

SMEs are very concerned because the newly introduced legislations are putting pressure on them as employers to be more responsible for elements outside their control (Budworth, 2000). In many SMEs, the employees have no union and more likely to be involved in more hazardous industrial sectors or those that rely on face-toface contact with customers (Walters and James, 1998). SMEs are usually involved in industries that are not technologically adaptable or those which are not flexible in their work organization (EF, 1997; Sorensen et al., 2007).

According to Dupre (2001), the "risk of having an accident at work is higher for workers in companies with fewer than 50 employees and for the selfemployed". These figures varies according to factors such as: Patterns of work; whether there have been reduction in manufacturing and increase in service industries; whether the most hazardous aspects of business had been contracted out by large firms to SMEs; whether the work involved labour-intensive tasks that rely on use of Personal Protective Equipment (PPE); demographic changes due to an aging working population (i.e., fewer injuries but more fatalities amongst older men at work). A review of empirical research reinforces the view that regulations and legislations can improve health and safety outcomes, but only if they meet strict conditions concerning senior management commitment, effective workforce involvement and program integration (Clare et al., 2003).

\subsection{Occupational Safety and Health Act (OSHA) in Malaysia}

Malaysia, during its transition from commodity based economy to an industrial based economy showed an increase in occupational accidents and illnesses and the inability of the enforcement agency owing to financial and human constraints to manage the situation (Farouk et al., 2011). Thus, in the year 1994, the Occupational Safety and Health Act 1994 (OSHA, 1994) was introduced in Malaysia, which provide a shift from the traditional command and control method of enforcement in which the government through DOSH assumed a huge responsibility in regulating the safety and health of workers at the workplace; to one of self-regulation, wherein all stakeholders at the workplace were responsible for promoting self-regulation with the ultimate responsibility vesting in the employer, as an alternative regulatory system (Farouk et al., 2011).

In Malaysia, the regulation on occupational safety is embedded into two acts: Factory and Machinery Act (FMA, 1967) focuses on technical issues; and Occupational Safety and Health Act (OSHA, 1994) focuses on management issues, both are enforced by Department of Occupational Safety and Health (DOSH). FMA (1967) assists the employer on how to identify, analyse and improve the ergonomics hazard. Limits are given as a requirement, when product or services exceed the national limits, some penalty will be liable to the employer (Sirat et al., 2011). Meanwhile, OSHA (1994) focuses on management issues to promote an occupational environment for persons at work which is adapted to their physiological and psychological needs. Within large companies, the evolution towards improvements of Occupational Safety and Health (OSH) practices was apparent with many of them voluntarily implement various types of occupational safety and health management system (Leman et al., 2010). In many past researches carried out in Europe, the level of occupational safety within multinationals and large companies were high but in SMEs premises they are below the minimum standards (Jeynes, 1999).

In Malaysia, via section 30 of the OSHA (1994) workplaces with 40 or more employees are mandated to establish Joint Occupational Safety And Health Committees (JOSHCs). In addition, Regulation 5(2) of the Occupational Safety and Health Committee Regulations 1996 (OSHCR, 1996) stipulates that the composition of the JOSHCs must at least have an equal number of management and non-management representatives. Thus a collective perusal of the OSHA (1994) and the OSHCR (1996) prompts one to conclude that the JOSHC is a distinctive feature in the self-regulatory system adopted in Malaysia (Farouk et al., 2011).

The two main objectives of this study are: First, indentify level of conformance to OSHA (1994) and 
second, investigate the reasons of their nonconformity among SMEs in chemical industry sub-sectors in Malaysia. Past studies conducted by researchers such as Onn (1999); Man (2000); Ng and Selva (2003) and Piah (2005) reported that SMEs workplaces are prone to accidents and illness.

\section{MATERIALS AND METHODS}

The important elements studied in this research are the SMEs conformity, top management's perceptions and competencies with respect to characteristics found in FMA (1967) and OSHA (1994) regulations in Malaysia.

The survey methodology was employed to determine three main dimensions (i.e., level of conformity, perception and competencies) of SMEs in chemical industry sub-sectors. These three dimensions are very important in this research, therefore various reliability and validity tests were conducted on the survey questionnaire. The survey questionnaire was used to collect data on SMEs conformity or non-conformity and state of readiness in chemical industry sub-sectors in implementing FMA (1967) and OSHA (1994).

The survey questionnaire was validated by 20 health and safety executives or managers working in SMEs. The questionnaire has a high reliability and validity value because more than $80 \%$ of the respondents agreed that the questions are suitable to measure SMEs conformity, top management's perception and competency with respect to FMA (1967) and OSHA (1994).

Reliability is the extent to which a score from a selection of measures that is stable and free from error. One way to determine the reliability of a test is to look at the consistency in which a respondent responds to items measuring a similar dimension. The extent to which same items are answered in similar ways is referred to as internal consistency and measures items stability. In general, longer tests may provide results with higher internal consistency, i.e., the agreement among the responses to the various test items (Herman, 2004; Chua, 2006).

Cronbach's alpha can be used to determine the research instrument's internal reliability (Herman, 2004; Chua, 2006; Sekaran, 2006). According to Pallant (2001), Cronbach's alpha is the most commonly reported measure of internal reliability and the median internal reliability coefficient of 0.7 found in the research literature is acceptable. The result of the pilot survey shows the value for Cronbach's alpha is 0.945 , which can be concluded that survey instrument has a high reliability.

Data gathering takes about 3 months beginning in November 2009 until January 2010. The survey was carried out in SMEs located in Klang Valley, Johor, Kedah, Kelantan, Penang and Sabah involved in chemical industry sub-sectors. In Malaysia, there are 1047 SMEs involved in chemical industry sub-sectors. According to Roscoe (1975), sample sizes larger than 30 and less than 500 are appropriate for most research. In total 41 survey questionnaires were completed and returned. The data obtained was analyzed using Statistical Package for Social Science (SPSS) for Windows Version 16 and followed the guidelines provided by Pallant (2001). Descriptive statistical method was used to calculate the data as well as to report the results such as percentage, mean and standard deviation. Inferential method (Spearman correlation coefficient and t-test) are based on the examples described by Herman (2004) and Chua (2006).

\section{RESULTS}

There are 12 items in the research instrument that measures conformity of the responding company towards $\mathrm{OSH}$ regulation. As such the total maximum score would be 60 . To determine the level of conformity, the score is translated into the mean range.

A mean score $\geq 4.0$ shows the respondent's company is considered to conform to the OSH regulation. A mean score of 3.0 to 3.9 would put the respondent's company to be in the intermediate level of conformity which reflects the respondent is not conforming to the $\mathrm{OSH}$ regulation and but steps are taken towards conformity. Only respondents companies with score $\leq 2.9$ are regarded as not conform to OSH regulation. The results of the conformity level are shown in Table 1.

Among the total 41 respondents SMEs from the chemical industry sub-sectors, only three companies had actually conformed to OSH regulation. For chemical industry sub-sector, majority of the respondents $(56.2 \%)$ were within the intermediate level while $(36.5 \%)$ had not conformed.

\subsection{Competency among Top Management}

In order to carry out the analysis for Competency among the Top Management, the score is transformed into the mean range. By achieving a mean score of 4.0 or more, the top management of the company is considered to be sufficiently competent for implementing the OSH regulation in their respective companies. A mean score of less than 2.9 indicates the top management is not competent to implement the $\mathrm{OSH}$ regulation within their companies. A mean score of 3.0 to 3.9 indicates the top management is not yet competent and they need some effort to reach the required competency level. The competency levels of the respondents are summarized in Table 2. 
Table 1. Result of the conformity level

\begin{tabular}{lllll}
\hline & $\begin{array}{l}\text { Not } \\
\text { Conform }\end{array}$ & Intermediate & Conform & Total \\
\hline $\begin{array}{l}\text { Chemical } \\
\text { industry }\end{array}$ & $36.5 \%$ & $56.2 \%$ & $7.3 \%$ & $100 \%$ \\
\hline
\end{tabular}

Table 2. Result of competency among top management

\begin{tabular}{lllll}
\hline & $\begin{array}{l}\text { Not } \\
\text { Conform }\end{array}$ & Intermediate & Conform & Total \\
\hline $\begin{array}{l}\text { Chemical } \\
\text { industry }\end{array}$ & $4.88 \%$ & $87.8 \%$ & $7.32 \%$ & $100 \%$ \\
\hline
\end{tabular}

Table 3. Reasons for not conforming to OSH regulations

\begin{tabular}{llr}
\hline Ranking & Reason & Percentage \\
\hline 1 & No knowledge & 34.9 \\
2 & Difficult and Expensive & 27.9 \\
3 & Low Risk & 23.3 \\
4 & Not aware & 7.0 \\
5 & Following Others & 2.3 \\
6 & No Advantage & 2.3 \\
7 & No description & 2.3 \\
& Total & 100.0 \\
\hline
\end{tabular}

\subsection{Reasons for Non-Conformity}

The respondents were asked the reasons why their companies were unable to conform to the OSH regulation. All the respondents answered this question and none had offered an alternative reason than those offered in the survey questionnaire. Only, $10 \%$ of the respondents believed that they are conforming and majority (90\%) of them admitted that they are not conforming to the OSH regulation. The reasons ranking and percentage of nonconforming to $\mathrm{OSH}$ regulation are shown in Table 3 .

From the seven reasons offered, the respondents can only choose five of them. The top three reasons selected by the respondents are: The lack of staff with knowledge on how to implement and comply with OSH regulation (34.9\%); followed by a negative perception that it is difficult and expensive to comply with the regulation (27.9\%) and the respondents believe that they are working in low risk work environment (23.3\%).

\section{DISCUSSION}

In general, the result shown in Table $\mathbf{1}$ indicates that a large majority of SMEs factories within the chemical industry sub-sectors had not conforms to OSH regulation. A study by Jeynes (2002) in Europe also found low compliance of small industries towards OSH regulations. Similarly, in this survey it was found that about $80 \%$ of the respondents had admitted not complying with OSH regulation or having little knowledge of $\mathrm{OSH}$ management systems and only reacted to the problem as it arise.

Referring to Table 2, only $7.32 \%$ of respondents can be considered to be competent in terms of having appropriate knowledge, skill and ability in carrying out OSH regulation within their respective organizations. The remaining respondents can be considered not competent, with majority in the intermediate level $(87.80 \%)$. Only $4.88 \%$ of respondents fall into the bottom category where they have no ability, skill or knowledge to implement $\mathrm{OSH}$ regulation at the workplace.

The top two reasons (i.e. lack of staff with knowledge on how to implement and comply with OSH regulation; and a negative perception that it is difficult and expensive to comply with the regulation are similar to the findings of a previous study done in Europe when the European Union (EU) directives were first implemented.

As regards to the lack of knowledge, the European Commission had acknowledged the problem and specifically state that guidance aimed at small firms should be made "helpful and effective in implementation of legal provisions" (EC, 1999). The regulation and ways to implement them also should be clear and any publication of a range of tools should be aimed at the man in the street (UNICE 2182/26).

The financial constraint issue is also a barrier that had been found to exist in SMEs in Europe. There is a perception that it will cost money to comply with all relevant health and safety laws and in some situations this may be the case (Wright, 1998; Vassie and Cox, 1998). Ultimately the burden of compliance falls disproportionately on the smallest firms. In this study, cost is not the primary concern of research respondents; however it is an important issue when putting necessary measures into place. Jeynes (2002) believe that particular evaluation on the type of help (i.e., level of expertise needed and the required financial outlay) should be carried out first.

\section{CONCLUSION}

Survey is a common technique in this field of research. However, it does not provide any empirical evidence on the effectiveness of management instruments on occupational risk prevention. Safety starts at the top. In many companies, a zero-accident policy is part of official company statements. However, it is a 
well-known gap between policy and practice because there is sufficiently strong evidence to conclude that SMEs employees are subjected to higher risks than the employees in large companies and SMEs have difficulties in controlling risk (Hasle and Limborg, 2006). In reality, policy needs to be supported by management's actions at the shop-floor level.

Within its due limitations, the study was able to provide answer to all the objectives. The survey result indicates; the overall level of conformity is still low among respondents that participated in the survey of SMEs in the chemical industry sub-sectors. There is a positive perception of $\mathrm{OSH}$ regulation among top managers of the responding SMEs. Unfortunately, the positive perception was not translated into a better conformity towards the OSH regulation. The survey result revealed that there is a strong relationship between the competency of top managers and conformity towards $\mathrm{OSH}$ regulation in SMEs. However, an overwhelming majority of the top managers in the SMEs surveyed were not competent to implement $\mathrm{OSH}$ requirement within their organization. The two main barriers indicated by the respondents are due to lack of staff with the required know-how and financial resources to implement OSH regulation. The survey indicates that majority of the SMEs either did not have any OSH management systems or only has very little OSH expertise. On overall, the survey had indicated that there is still much need to be done in promoting more SMEs to conform to OSH regulation in their workplace. To achieve this, the Malaysian government through its agencies such as DOSH, NIOSH and National Council for Occupational Safety and Health are urged to intensify their efforts in promoting $\mathrm{OSH}$ awareness by visiting their premises, conducting seminars, workshops, road-shows and publishing articles in the local mass media.

\section{ACKNOWLEDGMENT}

The researchers would like to acknowledge the financial contributions both from Ministry of Higher Education and Universiti Kebangsaan Malaysia for their research grants, UKM-GUP-2011-039.

\section{REFERENCES}

Bahari, I., 2006. Pengurusan Keselamatan dan Kesihatan Pekerjaan. 2nd Edn., Kuala Lumpur McGraw-Hill, Malaysia, ISBN-10: 9833219357, pp: 395.

Budworth, T., 2000. Future challenges for insurance and risk management. Proceedings of the IOSH Conference, (IOSHC' 00).
Champoux, D. and J.P. Brun, 2003. Occupational health and safety management in small size enterprises: An overview of the situation and avenues for intervention and research. Safety Sci., 41: 301-318. DOI: 10.1016/S0925-7535(02)00043-7

Chua, Y.P., 2006. Asas Statistik Penyelidikan. 1st Edn., McGraw-Hill, Kuala Lumpur, ISBN-10: 9833219489, pp: 221.

Clare, G., U. Elsa and R. Malcolm, 2003. Occupational safety and health management systems in Australia: Barriers to success. Policy Practice Health Safety, 2: 67-81.

Dupre, D., 2001. Accidents at work in the EU 19981999. Statistics in Focus Theme 3Eurostat, pp: 1-8.

EC, 1999. Health and Safety at Work in Europe-where next? European Commission.

EF, 1997. Working conditions in the European Union. EC.

Farouk, U. K., S. Richardson and A.J.S. Santhapparaj, 2011. Joint Occupational Safety and Health Committees: Extent of Functioning in Malaysian Manufacturing Companies. IACSIT Press.

FMA, 1967. Factories and Machinery Act (Act 139: 1967) and Regulations and Rules, Malaysia (2008). International Law Book Services.

Hasle, P. and H. J. Limborg, 2006. A review of the literature on preventive occupational health and safety activities in small enterprises. Indus. Health, 44: 6-12. DOI: 10.2486/indhealth.44.6

Hassan, K.H., 2003. Industrial Safety Law in Malaysia. Dewan Bahasa dan Pustaka.

Herman, I., 2004. Statistics and Data Analysis for Social Sciences. Ustaras Publisher.

Hussin, Z., J.S. Yew and Z. Zakaria, 2005. The standard implementation of Occupational Safety and Health Act (OSHA) in Small and Medium-Sized Industries (SMIs) Kedah.

Jeynes, J., 1999. Small firms and challenges of changing working life. Proceedings of the Finnish $\mathrm{IOH}$ Symposium, (FIOHS' 99).

Jeynes, J., 2002. The impact of European legislation on health and safety in small firms. Aston University, United Kingdom.

Leman, A.M., A.R. Omar and M.Z.M. Yusof, 2010. Monitoring of Welding Work Environment in Small and Medium Industries (SMIs). IJRRAS 5: 18-26.

Man, A.B.C., 2000. OSH for SMIs: Some proposals for long term solution-the government perspective. Proceedings of the at NIOSH 3rd Conference, Bangi, Selangor, Malaysia. 
Ng, W.K. and P. Selva, 2003. OSH profile in the service sector in particular the small and medium sized enterprise. Proceedings of the Malaysian Trade Union Congress Labour Bulletin, (LB' 03).

Onn, A., 1999. NIOSH: Future directions for the new millennium. Proceedings of the NIOSH 2nd Conference on Occupational Safety and Health, (OSH' 99), Bangi, Selangor.

OSHA, 1994. Occupational Safety and Health Act (Act 514: 1994) and Regulations and Orders. Government of Malaysia.

OSHCR, 1996. Occupational Safety and Health Committee Regulations. Government of Malaysia.

Pallant, J. 2001. SPSS Survival Manual. Open University Press, Philadelphia.

Piah, O.M., 2005. Level of safety culture at major hazard installation in Malaysia. Universiti Kebangsaan Malaysia, Malaysia.

Roscoe, J.T., 1975. Fundamental Research Statistics for the Behavioral Sciences. 2nd Edn., Holt, Rinehart and Winston, New York, ISBN-10: 0030919347; pp: 483 .

Sekaran, U., 2006. Research Methods for Business: A Skill Building Approach. 1st Edn., John Wiley and Sons Inc., ISBN-10: 0470145986.

Sirat, R.M., A.M. Saaharoum and S.A.H. S. Hassan, 2011. The Influence of Ergonomics on Occupational Safety and Health (OSH) Legislation in Malaysia. Proceedings of the International Conference on Industrial Engineering and Operations Management, (EOM' 11), Kuala Lumpur, Malaysia, pp: 839-844.
Sorensen, O.H., P. Hasle and E. Bach, 2007. Working in small enterprises-is there a special risk? Safety Sci., 45: 1044-1059. DOI: 10.1016/j.ssci.2006.09.005

Swuste, P., 2008. "You will only see it, if you understand it" or occupational risk prevention from a management perspective. Hum. Factors Ergonom. Manufactur., 18: 438-453. DOI: 10.1002/hfm.20101

Takala, J., 1993. Associations between occupational hazards detected with log-linear statistical methods. Safety Sci., 17: 13-28. DOI: 10.1016/09257535(93)90017-8

Vassie, L. and S. Cox, 1998. SME interest in voluntary certification schemes for Hands. Safety Sci. J., 29: 67-73.

Walker, D. and R. Tait, 2004. Health and safety management in small enterprises: An effective low cost approach. Safety Sci., 42: 69-83. DOI: 10.1016/S0925-7535(02)00068-1

Walters, D. and P. James, 1998. Roben's RevisitedThe Case for a Review of Occupational Health and Safety Regulation. Institute of Employment Rights.

Wright, M., 1998. Factors motivating proactive H and S management. HSE Contract Report 179/1998. 